\title{
A Conversation with Steve Henikoff
}

\author{
INTERVIEWER: RICHARD SEVER \\ Assistant Director, Cold Spring Harbor Laboratory Press
}

Steve Henikoff is a Member, Basic Sciences Division of the Fred Hutchinson Cancer Center and an Investigator at the Howard Hughes Medical Institute.

Richard Sever: You work with a veritable alphabet soup of centromere-associated proteins. Could you tell us a bit about the history of centromeres?

Dr. Henikoff: Walter Fleming introduced the term "chromatin" in 1882, so chromatin actually precedes the rediscovery of Mendel's laws, precedes the beginning of genetics. What he called chromatin was in these drawings of chromosome segregation in, I think it was newt: beautiful drawings of chromosomes that were being pulled to the poles at mitosis. What was particularly striking was that you could see everything. You saw the centrosome; you saw the spindle fibers that were holding onto the chromosomes. He was very careful to show a little darkening for each of the connections between the spindle fiber and the chromosome. He actually saw centromeres, or heterochromatin as we call it now, pericentric regions, whatever. He saw them and he colored them in. So actually, centromeres were discovered before the chromosome theory of heredity. Centromeres were really the first genetic loci, after Mendel's work.

The beginning of the molecular study of centromeres was this paper from Louise Clark and John Carbon where they showed that if you take a little piece of DNA that comes from the genetically mapped centromere and put it on a plasmid, you make a chromosome that will segregate normally during both mitosis and meiosis. That proved that that piece of DNA was the centromere. I remember when that paper came out, it was quite revolutionary. I thought, "Oh! They're all gonna be that way." We were studying heterochromatin in Drosophila at the time, and I thought it would really be very simple because in there among all those repeated sequences that we can't make any sense out of, there's going to be some little magic sequence. But that was not to be.

A lot of progress was made studying the budding yeast centromere, and even fission yeast turned out to be different. It turned out that nearly all multicellular organisms have centromeres that are highly repetitive tandem sequences. There was a lot of skepticism at the time that centromeres were just going to be homogeneous alpha satellite repeats, for example-which turns out to be what our centromeres are composed of. Other people thought it might be other satellites, until there was the experiment by Hunt Willard and his colleagues showing that you can actually make artificial centromeres. It's the equivalent of the yeast experiment, but you can do it with human centromeres. But you needed long arrays of these alpha satellite sequences, so that was a problem.

Then there was the fact that in 2000 or 2001, the draft human genome was published. It's still a gap at all of our centromeres. We haven't assembled it yet, because it's so homogeneous you can't do much with it. It's been difficult to study. But a lot of progress has been made in understanding centromeres, particularly in yeast. That's our best example.

Richard Sever: How long is that dedicated sequence in budding yeast?

Dr. Henikoff: It's one hundred twenty base pairs. It varies a little bit between chromosomes; there are sixteen chromosomes. They have canonical sequences that comprise the first element, which is about eight base pairs long, and that's a binding site for a transcription factor. On the other end, there is the binding site for a kinetochore-specific complex that recruits the centromeric nucleosome that sits in the middle, but there are only about eighty base pairs for that. People have been wondering, how do you get a nucleosome at eighty base pairs? This has been a bit of a controversy. It's pretty well established that it's the smaller particles. They're only four histones in there, probably, because that's all that you can really wrap eighty base pairs around.

I don't think that's been so much of a problem. Where it's really turned out to be a problem are the satellite centromeres: the ones in humans, plants, and most higher eukaryotes.

Richard Sever: These "satellite centromeres" are the alpha satellite sequences? What exactly are those?

Dr. Henikoff: The alpha satellite is a one hundred seventy or so base pair unit that gets repeated multiple times. It's almost homogeneous, but importantly, there are these higher order repeats. In our genome, for example, the majority of the alpha satellites for most of our chromosomes is a fundamental dimeric unit. These units might only be about $60 \%$ or so identical, one to the next, so

(C) 2017 Henikoff. This article is distributed under the terms of the Creative Commons Attribution-NonCommercial License, which permits reuse and redistribution, except for commercial purposes, provided that the original author and source are credited. 
they're really very different from each other. But then you go to the next one, where that dimer gets repeated, et cetera, in the same orientation. It's very homogeneous, but then sometimes there's enough divergence that you'll see that there are higher orders above that: there's dimers, there's tetramers, et cetera. Usually, it's even-numbered ones for most of the chromosomes, but three of our chromosomes have an odd number. Five is the basic number. So it gets very complicated from chromosome to chromosome. That's been one of the problems.

Mouse centromeres are much simpler. They only have two different satellite repeats. One of them, the minor, has a one hundred twenty base pair repeat unit, and the major has a two hundred thirty-four base repeat unit, and they don't see higher order structures. The higher order structures are something that you find in primates but you don't find it in some others. We've been looking a lot into Arabidopsis; plants have the same kind of structure. They have a 178 base pair repeat unit, but they don't have higher order structures.

I can go through all these examples, but the one thing that's in common is that there are these highly repetitive sequences that are there, and that makes for an interesting challenge to study them. But it also asks the question: Why is it like that?

Richard Sever: Given this is such a fundamental thing that's shared by anything that needs to segregate its sister chromatids - which is everything - why is it all so different?

Dr. Henikoff: We have a hypothesis that we refer to as centromere meiotic drive. It only occurs in female meiosis. Female meiosis is asymmetric. Of the four products of meiosis, only one of them will get chosen to go to the next generation. There's the egg pole, and then there's the pole that will give you the polar bodies. In other words, only one of the four products will move to the egg pole. It turns out that there is a reorientation process, because there's a competition between centromeres from the maternal side, and centromeres from the paternal side.

Richard Sever: So we're back to selfish genes.

Dr. Henikoff: It's absolutely selfish. We'd actually proposed that centromere drive is a process in which there's a reorientation. There's a competition between the maternal and the paternal side and because of that competition centromeres are competing to make it into the egg pole. They're the most selfish elements that can be. They're just repeat sequences, and so the bigger centromeres in some organisms make it to the egg pole. That was shown very nicely in work from Ben Black and from Mike Lampson, who showed that this actually occurs in mouse, and they worked out a lot of the details of the process. So, we think that the "why" is that centromeres are competing, and they're rapidly evolving because of it. It's a Darwinian process of cheating in female meiosis.

Richard Sever: The next level, which is all of this alphabet soup of proteins coming in, is probably more conserved.
Dr. Henikoff: No, actually. It turns out it's an arms race. Harmit Malik, when he was a postdoc in the lab, discovered that CENP-A - centromere protein A-which is the centromeric histone, which is absolutely essential to everything...

Richard Sever: This is the thing that replaces the regular histone $\mathrm{H}$...

Dr. Henikoff: Right. The H3 variant-we were working on in Drosophila, but it turns out to be more generalitself was showing rapid evolution. What Malik discovered was that you see a large excess of replacement, over synonymous, changes. We know about arms races where this can occur between a pathogen and the host immune system. A virus' coat protein will mutate to evade immune surveillance, and then the host immune system will clobber it, so you get this arms race going, and it builds up changes on the surface of the viral coat part. We see the same kind of process must have been occurring for the centromeric histone. But how could that be? That's going to be deleterious, and you'll be dead, because every cell division's going to die.

We found that for CENP-A, for CENP-C, basic centromeric proteins are undergoing an arms race, and female meiosis is the only time when you can actually have an arms race. We call that the centromere paradox: Why is it that centromeric sequences are evolving so rapidly, both in the size of the centromeres-your Y chromosome and mine might differ by an order of magnitude in size; they differ tremendously - yet they're doing the most basic process we know of in genetics, which is chromosome segregation, which is very stable. How could that be? We think it's this arms race of female meiosis. That was fifteen or so years ago, and I think it's holding up pretty well.

Richard Sever: You mentioned CENP-A, and you've noted there are others: CENP-B, -C, -TWSX, -Z. This is a giant protein complex on top of the DNA that links to the kinetochore or attaches to microtubules, correct?

Dr. Henikoff: That's right. It's on the DNA. The DNA wraps around the nucleosome part; it also wraps around CENP-TWSX. There's a complex of histone fold proteins that the DNA wraps around. What's important about that is there're two connections to the outer kinetochore. There's been some question as to where those connections come from, at the chromatin level. One connection is CENP-T, and one is CENP-C. That's where we get into alphabet soup. CENP-T has partners: W, S, and X. CENP-A has partners: H4, H2A, and H2B. If you think about it like that, you've got two parts that connect. What we show is that they're all actually part of one coherent complex. We showed this in a couple different ways, including a new method that we call "CUT\&RUN" [Cleavage Under Targets and Release Using Nuclease].

Richard Sever: Everybody was familiar with ChIP-seq, where you bind your antibody onto the protein and you sonicate away all DNA. This seems like a much cleaner way to get a better signal. 
Dr. Henikoff: This is a method that was introduced in 2004 by Ulrich Laemmli, however it really hadn't been used since until we started working on this and improving the protocol. We're starting out with intact cells, as opposed to breaking everything up like you do for ChIP. Everything stays intact. We then permeabilize them in such a way that we can get antibodies to go in and find their targets in the chromatin, say, for a transcription factor or a centromere protein. Then we add a fusion between protein A and micrococcal nuclease. Protein Awill bind to the immunoglobulin $\mathrm{G}$ of the antibody, so therefore you're tethering this micrococcal nuclease, which is our standard tool for looking at chromatin.

Once it's tethered, it has some very nice properties. We can put it at low temperature so it'll just stay in place during the reaction. Micrococcal nuclease requires calcium, so it's not going to do anything until you add the calcium. You add the calcium, let it go for a few seconds or an hour or something, it doesn't seem to matter. It will cut out on both sides the particle, and then it'll float out through the nuclear pores and we just take the supernatants and extract the DNA, and it's very simple. Our current protocol takes about half a day. It could even take just a couple hours.

Being clean is important when you're looking at something like a centromere where there's only one per chromosome, or transcription factors where you have one here that has a footprint of about twenty base pairs and another here of twenty base pairs, and you've got ten kilobases in between. Basically, when you chew up the whole DNA like you do with ChIP, you're going to have a certain probability of every little piece of DNA getting sequenced, and that's going to give you a lot of background. It might be a low background, but you'll have to do a lot of sequencing in order to see those peaks. With CUT\&RUN, because we leave the vast majority of the DNA behind on the beads and only sequence what gets released and floats out, the background really goes way down, such that we only have to sequence about a tenth as deeply. And because the antibody is not looking at the whole cell contents that get ground up when you do ChIP but only seeing the intact cells and the nucleus, it's only seeing the surfaces. That means that the antibody binding's usually very efficient. For a histone modification, we can get down to a hundred cells, so it should be good for low cell numbers. It's all new, but a lot of people are trying it, and I've been getting good reports. I think it's going to catch on.

Also, the ChIP method is destructive because at some point, before you add the antibody, you solubilize everything and you can lose some parts. That's what we're finding: No matter how you solubilize it, whether you chew everything up with micrococcal nuclease or grind it up, it's going to cause some damage. With CUT\&RUN, the antibody's added when everything is intact. In fact, it's added at the time that you permeabilize the cell. They were live, and we get them as quickly as possible, and everything is intact. Because of that, I think we're getting a more accurate picture. What we see is quite compatible with what we've seen with ChIP, but I think it shows us that what we'd been looking at were, sort of, eroded particles. Actually, the intact particles are much larger than what we thought typically: over one hundred eighty base pairs over this dimeric repeat unit of three hundred and forty. Because they're larger, they can accommodate a lot of the alphabet soup of proteins that we see there, including the ones I've just talked about. We can see that they're all there. 


\section{$\$_{\text {CSH\& }}^{\infty}$ Cold Spring Harbor Symposia SYMPOSIA}

\section{A Conversation with Steve Henikoff}

Cold Spring Harb Symp Quant Biol 2017 82: 391-393 originally published online April 2, 2018 Access the most recent version at doi:10.1101/sqb.2017.82.034785

Creative This article is distributed under the terms of the

Commons http://creativecommons.org/licenses/by-nc/4.0/, which permits reuse and

License redistribution, except for commercial purposes, provided that the original author and source are credited.

Email Alerting Receive free email alerts when new articles cite this article - sign up in Service the box at the top right corner of the article or click here. 